\title{
Developing a Culturally Adaptive Pathway to Success: Implementation Progress and Project Findings
}

\section{Dr. Eun-Young Kang, California State University, Los Angeles}

Eun-Young Elaine Kang, Ph.D., is a professor in the Department of Computer Science of the College of Engineering, Computer Science, and Technology at Cal State LA and currently serves as Chair of the Computer Science Department. Her research interests are in Computer Vision, Computer Graphics, Augmented/Mixed Reality, and Game Programming. She has served as principal undergraduate advisor for the Computer Science department for several years. Also, she has served as PI/Co-PI on multiple educational projects sponsored by NSF programs including NSF S-STEM, NSF GK-12, and NSF TUES.

\section{Dr. Jianyu "Jane" Dong, California State University, Los Angeles}

Jianyu Dong is a professor in electrical and computer engineering and currently serves as the Associate Dean for the College of Engineering, Computer Science, and Technology at Cal State LA. Her area of expertise is video compression/communication, multimedia networks, QoS, etc. With a strong passion in Engineering Education, she has been engaged in multiple funded projects and initiatives to increase the participation and success of students from undeserved, low-income communities in engineering areas.

matthew jackson PhD, California State University, Los Angeles

Matthew Jackson is an Assistant Professor in the Department of Psychology at California State University, Los Angeles. His research examines how the intersections of social identities shape the academic attitudes and behaviors of students.

\section{Dr. Emily L. Allen, California State University, Los Angeles}

Emily L. Allen, Ph.D., is Dean of the College of Engineering, Computer Science, and Technology at California State University, Los Angeles. She believes in a collaborative, student-centered approach to research, education, academic administration and leadership. She currently chairs the ASEE Engineering Deans Council Diversity Committee, and serves on the ABET Academic Affairs Council, the TMS Accreditation Committee, and the National Board of Directors for the Society of Hispanic Professional Engineers. Dr. Allen earned her BS in metallurgy and materials science from Columbia University, and her MS and PhD in materials science and engineering from Stanford University. She previously served as faculty, chair and Associate Dean at San Jose State University's College of Engineering.

\section{Dr. Daniel Galvan, California State University, Los Angeles}

Dr. Daniel Galvan is Director of Acceleration Initiatives and Student Engagement in the College of Engineering, Computer Science, and Technology at California State University, Los Angeles. He has an extensive background in facilitating asset-based approaches towards teaching through equity-minded workshops in community colleges, public, and private four-year institutions. He received his BA in Sociology from Cal Poly San Luis Obispo, his MA in Higher Education and Student Affairs from New York University, and his Ed.D. in Educational Leadership from University of Southern California. 


\section{Developing a Culturally Adaptive Pathway to Success: Implementation Progress and Project Findings}

\section{Introduction}

It has been well recognized that the financial disadvantage of low-income students is not the sole barrier to their academic success. With a mission to increase the number of academically talented low-income students entering the STEM workforce, the NSF S-STEM program has granted awards to various type of institutions in order to advance our understanding of how "evidencebased curricular and co-curricular activities affect the success, retention, transfer, academic and career pathways, and graduation in STEM of low-income students" [1]. To date there are a number of publications that document effective practices and strategies to help talented lowincome students succeed in different institutional and disciplinary contexts [2], [3]. Our project builds on this literature by providing a combination of an academic scholarship and culturally competent mentorship for students at a Very High-enrolled Hispanic Serving institution (VHHSI).

Designated as a Title III minority-serving institution, the College of Engineering, Computer Science, and Technology (ECST) at California State University Los Angeles (Cal State LA) has a student body of which $63 \%$ are underrepresented minority (URM) students; $60 \%$ are firstgeneration college students; and $70 \%$ of the students are Pell grant eligible and need to work for more than 20 hours per week to support themselves. In addition to financial disadvantage, many students - including those who are academically talented - have inadequate preparation for the increased rigors of college education from their K-12 education and limited family guidance due to the fact that most students are first generation college students. With support from NSF Scholarships in Science, Technology, Engineering, and Mathematics (S-STEM), the Culturally Adaptive Pathway to Success (CAPS) program aims to build an inclusive pathway to accelerate the graduation for academically talented, low-income students in Engineering (Civil Engineering, Electrical Engineering, and Mechanical Engineering) and Computer Science majors at Cal State LA, which traditionally serves the underrepresented and educationally disadvantaged minority students in the Los Angeles area.

CAPS program aims to build a pathway progressively developing social and career competence in our students via three integrated interventions: (1) Mentor+, a relationally informed advising strategy that encourages students to see their academic work in relation to their families and communities; (2) peer cohorts, providing social support structure for students and enhancing their sense of belonging in engineering and computer science classrooms and beyond; and (3) professional development from faculty who have been trained in difference-education theory, so that they can support students with varying levels of understanding of the antecedents of college success. To ensure success of these interventions, the CAPS program places great emphasis on developing culturally responsive advisement methods and training faculty mentors to facilitate creating a culture of culturally adaptive advising. More details of CAPS interventions can be found in [4].

CAPS program is a 5-year project that started fall 2018. The program planned to support two cohorts of 14 scholars from their sophomore to senior years. This paper presents CAPS program 
implementation progress during the first two project years (fall 2018 - fall 2019). In particular, we will share the changes that we have made after the first project year (fall 2018 - summer 2019) to improve several key components of the program - recruitment, cohort building, and mentor training. We will also report findings of the following CAPS research questions: (a) how did CAPS interventions affect the development of social belonging and engineering identity of CAPS scholars, and (b) what was the impact of Mentor+ on academic resilience and progress to degree. The program conducted qualitative data collection and analysis via focus group meetings and interviews as well as quantitative data collection and analysis using academic records and surveys. The research findings will help enhance the CAPS program and establish a sustainable Scholars Support Program at the university that can be transferred to similar culturally diverse institutions to increase success for students who have socio-economic challenges, and can be used for all scholars in the College regardless of the source of their scholarships. The rest of the paper is organized as follows. Section two presents the program implementation during the first two project years with a focus on the improvements made during year 2; Sections three and four described the findings from research and program evaluation, as well as action plans for the future based on what we learned through the findings.

\section{First Two Year Implementations of CAPS Program}

\section{$\underline{\text { Recruitment }}$}

The program has established a structured process and successfully recruited two cohorts - the first cohort of 12 students in the fall 2018 and the second cohort of 16 students in the fall 2019. The process highly utilizes several online tools that the program created. Two main tools are a dedicated web portal to advertise the program and a secure online application platform. The recruitment process is as follows:

- In early February, the program hosts a scholarship information session in the college and advertises the opportunity through flyers, emails, college Kiosk TV, college webpages, enewsletters, student organizations, and announcements in classrooms.

- The program receives online scholarship applications. The application requires minimum academic information (e.g., GPA, Calculus I grade and ENGR 1500 grade) for efficient screening as student academic record is available on the university server, and it included an essay describing 1) how being awarded this scholarship would impact the applicant's life and 2) what the applicant's interests, motivation for study, and career goals are.

- When the application window closes in late March, the CAPS program selection committee reviews the online applications, essays, recommendation letters (optional), and academic records.

- Finalists are selected and notified by mid-April for interviews.

- Individual interviews are held by the CAPS selection committee, comprised of the CAPS PI and a Mentor+ faculty advisor from the applicant's department. Through interview questions, students were assessed on their potential for academic success, passion and dedication to the STEM field and what obstacles they perceive to pursuing their goals. Each interviewer thoroughly documented interview answers and feedback.

- Scholars are finally selected based on four criteria: the funding agency criteria (citizenship and fulltime enrolment); academic ability (e.g., GPA); financial need as determined by the campus financial aid office; and their potential to succeed based on 
their application and interview. Other criteria (such as Physics course grade) are also considered to narrow down the list further.

While establishing the recruitment process, one concentrated effort was to collaborate with other campus programs in order to create an efficient way to fill the applicant pool with highly eligible candidates. The CAPS team closely worked with the ECST First-Year Experience program (FYrE). FYrE is a first-year experience program for incoming freshmen who are Calculus-ready in the fall. It engages first-time freshmen by cohorting them in their Calculus and Physics courses, as well as in (1) a 3-unit course, Introduction to Engineering and Technology, which includes hands-on team design projects and culminates in an underwater robot design contest; (2) Introduction to Mechanics, a discovery-based course linking mathematics and physics, designed to improve critical thinking skills and prepare students for the physics sequence; (3) Supplemental Instruction, peer-facilitated workshops to support students' success in math and physics. As a majority of eligible CAPS candidates are part of FYrE, the CAPS program has established an official communication route to inform FYrE students of the CAPS scholarship opportunity and encourage them to apply. In fact, the FYrE and the CAPS have a joint Co-PI and a joint Professional Advisor. As a results, 8 out of 12 first year scholars were recruited from FYrE and 11 out of 16 second-year scholars were recruited from FYrE.

Even though the process had been clearly established, the PIs felt that the program did not receive enough applications during the first year recruitment, so the program added new efforts to strengthen the recruitment process. In particular, the program focused on reaching out students more broadly and motivating them to apply.

- Students are strongly motivated by peers. Thus, the program actively involved first-yearcohort scholars in the recruitment process. First-year-cohort scholars were invited to the information session to share their experiences in the CAPS program with prospective scholars and they were also encouraged to advertise the scholarship opportunity in their student organizations and clubs.

- Faculty mentors were tasked to reach out to students more personally. As CAPS mentors are serving as academic advisors in their department, they were asked to identify eligible candidates during their face-to-face advisement times and encourage students to apply. Many students applied for the scholarship program thanks to this personal encouragement.

- The program increased the number of announcements. More email announcements were sent out and more verbal announcements were done in classrooms and meetings by different groups of people including faculty, instructors, staff advisors, and students. During the information session, one student mentioned that he decided to attend the session due to so many email he received through different channels.

As a result of these changes, the program recruited more scholars for the second cohort (16 scholars) than the first cohort (12 scholars). Table 1 shows the distribution of students in the two CAPS cohorts. 26 of 28 recruited scholars (93\%) are either URM and/or female students. As of fall 2019, the program has not retained all the recruited students. Four scholars of the first cohort left the program. Table 1 shows the retained number of students by major, gender, and URM. Two were terminated due to unmet academic requirements and two left the college (transfers). 


\begin{tabular}{|c|c|c|c|c|c|c|c|c|c|}
\hline \multirow[t]{3}{*}{$\begin{array}{l}\text { Cohort } \\
\text { No. }\end{array}$} & \multirow[t]{3}{*}{ Major } & \multicolumn{4}{|c|}{$\begin{array}{l}\text { Number of Scholars } \\
\text { (Recruited) }\end{array}$} & \multicolumn{4}{|c|}{$\begin{array}{l}\text { Number of Scholars } \\
\text { (Retained as of Fall 2019) }\end{array}$} \\
\hline & & \multicolumn{2}{|c|}{ Male } & \multicolumn{2}{|c|}{ Female } & \multicolumn{2}{|c|}{ Male } & \multicolumn{2}{|c|}{ Female } \\
\hline & & URM & $\begin{array}{l}\text { Non- } \\
\text { URM }\end{array}$ & URM & $\begin{array}{l}\text { Non- } \\
\text { URM }\end{array}$ & URM & $\begin{array}{l}\text { Non- } \\
\text { URM }\end{array}$ & URM & $\begin{array}{l}\text { Non- } \\
\text { URM }\end{array}$ \\
\hline \multirow[t]{5}{*}{1} & Civil Engineering & & & & 2 & & & & 1 \\
\hline & Computer Science & 2 & & 1 & 2 & 1 & & 1 & 2 \\
\hline & Electrical Engineering & 2 & & & & 1 & & & \\
\hline & Mechanical Engineering & 1 & 1 & & 1 & & 1 & & 1 \\
\hline & $\begin{array}{l}\text { SubTotal } \\
\end{array}$ & 5 & 1 & 1 & 5 & 2 & 1 & 1 & 4 \\
\hline \multirow[t]{5}{*}{2} & Civil Engineering & 3 & & & & 3 & & & \\
\hline & Computer Science & 4 & & 1 & & 4 & & 1 & \\
\hline & Electrical Engineering & 4 & & 1 & & 4 & & 1 & \\
\hline & Mechanical Engineering & 2 & & 1 & & 2 & & 1 & \\
\hline & SubTotal & 13 & & 3 & & 13 & & 3 & \\
\hline \multicolumn{2}{|r|}{ SubTotal } & 18 & 1 & 4 & 5 & 15 & 1 & 4 & 4 \\
\hline & Total & & & & 28 & & & & 24 \\
\hline
\end{tabular}

\section{Mentor+: Mentor Training}

As indicated by many studies, advisor training is key to successful mentoring programs [5], [6]. Our previous work has shown that engineering faculty advisors can learn to provide more holistic advising, with the right professional development program [7], [8]. The CAPS program has worked on establishing professional development sessions for Mentor+ advisors, aiming to disseminate through the college's Advising Council [9] and the college's Teaching and Learning Academy [10].

Led by a social psychologist who is also a Co-PI on the project, the training for faculty mentors focuses on increasing the awareness of the benefits of holding growth mindsets [11], [12], [13] and developing a culturally responsive mentoring procedure. During the summer 18 - fall 19 period, three mentoring sessions took place following the culturally responsive mentoring strategy.

- The Summer 18 training session focused on a general overview of how to maximize the success of diverse engineering students. The training session presented three mindsets that can help maximize the success of our students. They are Growth mindset, Purpose and Value, and Social Belonging. Mentor+ advisors learned to encourage a growth mindset in students to maximize persistence in the face of challenges, help students make connections between their academic endeavors and their personal values to maximize interest and motivation, and regularly check in with students to ensure that they feel like they belong.

- The Fall 18 training session was designed to guide mentors to have effective first one-on-one meetings with each CAPS scholar. The training session focused on how to build rapport with them and encourage them to come to the mentor with both traditional challenges (i.e., failing an exam) and non-traditional challenges (i.e., feeling like they don't belong). The script-like meeting guidelines and checklist were provided for Mentor+ advisors to facilitate their 
building rapport with their mentees (scholars), especially including the reasons why their mentee decided to pursue their degree, and the goals that they have for themselves. These training items were also connected back to the mindsets that were discussed during the Summer18 training. Mentor+ advisors were given other guidelines such as reducing the intimidation that students might feel by sharing a bit about their personal journey to success or a challenge that they had to overcome, and/or a turning point when they first started to feel like they mastered their craft. At the end of the training, Mentor+ advisors outlined talking points to cover in their initial and subsequent meetings, as well as homework to give their mentee to help them get to know students. Mentor+ advisors were asked to record their observations after every meeting with each mentee.

- As continuous development of the mentor training, the program added a training session focusing on various aspects of intersectionality as it relates to individual's social identities, and how mentors can use these knowledge to better interact with mentees. The Fall 19 training session began with a warm-up activity where participants were asked to map out their social identities (e.g. race, age, gender, language, etc.) and reflect on how their most salient social identities may influence how their students/mentees may perceive them, and how they may present themselves. This warm-up activity included asking the participants (mentors), to reflect about their own experiences in interacting with their mentors while they were navigating their higher education experience, and to share how these past experiences may influence how they mentor current CAPS scholars. These warm-up activities set the tone for the rest of the training which focused on exploring the intersectionality of various social identities by 1) learning the difference between diversity, equity, and inclusion, 2) learning about gender identity and expression, and 3) learning ways to mentor CAPS scholars utilizing Yosso's Community Cultural Wealth framework [14]. At the conclusion of this mentor training, participants shared feeling better equipped to provide culturally sensitive mentoring.

- In the spring 20, due to the COVID-19, the program has developed the first online training for faculty mentors, which focuses on growth mindset.

- Training description: After providing definitions of growth (vs. fixed) mindsets, the pilot training mindset short course asked participants to predict the persistence patterns of students with growth mindsets after facing academic challenges during their transitions to college (i.e. GPA dropping from 2.8 to 2.5). Asking participants to both identify and to assess their own views is an established "active learning" technique, referred to as The Pre-Theoretic Intuitions Quiz, that encourages greater critical thinking in relation to subsequent course material (Faust \& Paulson, 1998). The use of this technique aims to help overcome the initial resistance of STEM faculty \& staff who are invested in selective models of student training where the faculty member's goal is to identify pre-existing talented students, as opposed to cultivating talent among students (and, thus, skeptical of the utility of growth mindsets). Participants were then exposed to research findings providing empirical evidence that students perform better when exposed to growth mindsets and that such exposure has been shown to help reduce achievement gaps for UR students relative to their well represented peers (e.g. Aronson, Fried, \& Good, 2002). Next, participants watched a 10 minute TED talk from Growth Mindset researcher Carol Dweck, which provided a fuller overview of the research supporting growth mindsets and academic achievement. After watching the video, participants are exposed to effective ways to 
communicate growth mindsets, as supported by prior research. Finally, Participants generated additional scenarios where they believe growth mindsets would be effective. This simple writing assignment is another active learning technique that facilitates deeper processing of the information presented in the short course, and prepares them to extrapolate the lesson to other contexts.

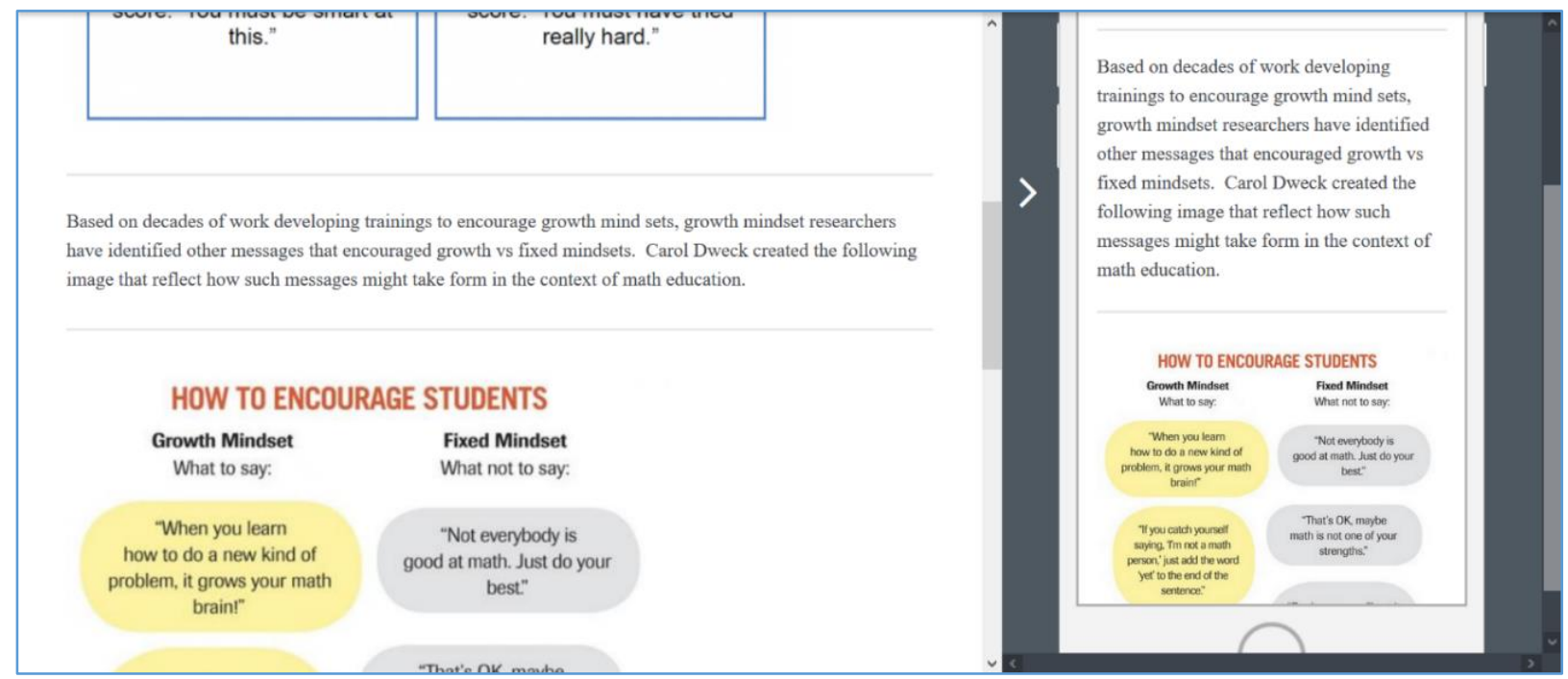

Snapshot preview of virtual training via computer or mobile device

\section{$\underline{\text { Mentor+: Scholar Mentoring }}$}

All CAPS scholars are paired with trained Mentor+ advisors from sophomore year until graduation. Mentor+ advisors consist of faculty mentors, a Professional Advisor from the college student advising center, and the CAPS PI. Scholars must meet Mentor+ advisor individually at least twice per semester to talk about their educational, personal and professional progress. Upon requests, frequency can increase. In every term, each scholar met a Mentor+ advisor (a Professional Advisor) more than once, the CAPS PI, and/or their faculty mentor. Faculty mentors conducted their individual meetings based on the guideline given through the training session. Scholars also met the professional advisor and the PI to review and plan their academic work, extra-curricular activities, fellowship opportunities, and discuss multi-tasking and time management. As for this mentoring, the program made one significant change after the first year. During the first project year, the program asked faculty mentors to contact scholars and initiate individual meetings. However, when students did not respond to faculty's meeting request in timely manner, faculty could not afford to follow up with scholars individually to rearrange meetings due to their busy schedules. Thus, faculty mentors could not meet certain scholars. To avoid this, from the second project year, the program had scholars initiate contacting their faculty mentors to arrange individual meetings. This change has worked very well to relieve faculty burden and ensured that each scholar met faculty mentor. Also, it has enabled scholars to be more proactive. On average, each scholar had 4 contact points (for mentor and advisement only). This is significantly higher than the average number of contact points ( 0 through 2 times) experienced by all other engineering sophomore students. 


\section{Activities for Cohort building}

Inspired by prior research [15], the program has adapted collaborative cohort activities promoting personal, professional development and strengthening cohort relationship across disciplines. Peer mentors have been shown to be effective in building communities, developing leadership skills, and increasing student retention and graduation [16], [17]. The program proposed to several cohort gatherings by award year (term cohort) and by major (major cohort). Major cohort gatherings are arranged at least twice per term - one with the designated faculty advisor. During the first project year, major cohort gathering was not very active due to small cohort size. Thus, peer-mentoring was not strong either. From the fall 2019 , as the program has more scholars with the second cohort, the program introduced a more scholar-oriented approach to facilitate the major cohort gatherings. The approach is to have a rotating voluntary leader per each major for each term arrange social meetings to build a supportive community focused on leadership development and academic, professional, and personal growth. This has been very effective and major cohort gathering and thus it was reported by scholars that peer mentoring have been more active for several majors. As for term cohort gatherings, the program hosted two gatherings (the orientation and social gathering) in every fall semester, focusing on icebreaker activities, getting to know each other, and sharing course work information and their personal experiences. The program looks forward to seeing closer cohort dynamics as we progress.

\section{$\underline{\text { Activities for Professional Development and Difference Education }}$}

Difference education is to prepare scholars to adapt themselves to new challenges. This is an important professional preparation for future career development. Detail information can be found in [4]. Our program embeds this within multiple activities like research activities, professional conference or seminar and field trips, where students are exposed to and experiences in working with a variety of people with different backgrounds and expectations. First of all, the program has provided abundant information for scholars about a series of seminars providing opportunities for discussion and presentations related to student success (e.g., time management, effective communication), research topics, and more from various campus student support centers, engineering research and design team projects (students and faculty), industry, etc. It also includes a series of seminars to help students to build their portfolio, review students' resume, and enhance required skills such as research, presentation, and interview skills.

Each term, while encouraging scholars to attend as many professional events as they can afford, the program required each scholar to attend at least one event (a seminar, presentation, industry visit, or workshop) and submit a reflection essay on their experience with memorable take-away points. In addition, the program encouraged scholars' participation in professional workshops, conferences, internship opportunities and research opportunities at other institutions (e.g., REU programs, STEM Advantage programs) to foster their educational and career goals. Several scholars participated in the professional conference (e.g., HENAAC, SHPE, CSUPERB), have been involved in research activities (e.g., Robotic lab, Bioengineering lab, and Quantum Physics lab) and apply for summer internships or REU programs. Identifying that not all scholars are active to contact people or seek opportunities, 
the program decided to 1) require scholars to initiate meetings with faculty mentors instead of faculty mentors initiating the meetings and 2) connect several faculty with relatively passive scholars to make them involved in undergraduate senior research projects. We expect that this minor change will give all the scholars a fair opportunity to train themselves to interact with their supervisors proactively and adapt themselves to new and challenging environments easily.

The program also provides field trips. Showing potential workplaces and career role models in their study field will help scholars to stay motivated, connect academic work to real world professions, and concretize their career vision. Scholars will visit local industry, national labs, infrastructures, public utilities, other research universities, professional workshops, conferences, and engineering construction projects. In the spring 2019, the program provided the first field trip to NASA Jet Propulsion Laboratory (JPL) to the scholar cohort group. A new (virtual) field trip is being arranged in the spring 2020.

\section{Program Impact on Scholars and Mentors}

The research activities in program aimed at enhancing the current understanding of four research questions outlined below (R.1 - R.4). To begin answering these questions, both qualitative and quantitative data collections occurred. An online survey was administered to the first cohort of CAPS scholars in summer of 2019 (i.e., after completion of the program's first year), assessing the impact of the CAPS program, engineering/computer science identity, and career plans. Seven Scholars completed the survey. A second group of students who are not CAPS scholars and matched on the academic qualifications that made students eligible for the CAPS scholarship - were recruited for the purpose of comparison in regards to the engineering/computer science identity and career plans. Of the 19 students that met the matching criteria, 7 started the survey, and 4 completed the survey. Due to the low sample sizes, statistical tests of differences were not conducted. However the trends of difference are reported below.

In addition, two focus group sessions were held at the end of fall semester 2019, one for each cohort of CAPS scholars. Sixteen scholars participated in the student focus groups (5 from the first cohort, and 11 from the second cohort). The focus group consisted of a semi-structured discussion with a moderator. The questions answered converged around four themes: the financial impact of the scholarship, the students ' relationships with their mentors, the students' perceptions of the CAPS program, and the students' recommendations for future program events. Finally, a CAPS mentor focus group was conducted in the form of a semi-structured discussion with a moderator. The questions answered converged around three themes: the mentors' relationships with their mentees, the mentors' perceptions of the mentees, and the mentors' recommendations for future program events. The findings of these data collections are reported below, as they relate to each research question.

(R.1a) What are students' perceptions of the obstacles they face and the resources available to them? 5 out of 7 CAPS scholars reported time management as their greatest challenge. The other two scholars reported concerns about ineffective teaching styles of their instructors (i.e. lacking a growth mindset and failing to communicate the real world utility of course content). Scholars reported a wide variety of resources used to address these challenges, including support from loved ones, peer support, study groups, calendars/schedules, and tutors. 
(R.1b) What are their perceptions of social belonging and their identity as engineers? Trends from our online survey reveal higher engineering identity for CAPS scholars relative to their matched peers (Table 2). In addition, CAPS scholars report greater recognition of their identity as engineers from their instructors, peers, and family as compared to their matched peers (Table 3).

\begin{tabular}{|c|c|c|}
\hline Table 2 & CAPS & NON CAPS \\
\hline & \multicolumn{2}{|c|}{ (1 = least strong, 5 = most strong) } \\
\hline Engineering/CS Identity & 3.90 & 3.58 \\
\hline
\end{tabular}

\begin{tabular}{|l|r|r|}
\hline Table 3 & CAPS & NON CAPS \\
\hline & \multicolumn{2}{|c|}{$(\mathbf{1}=$ Strongly not recognized, 7 = Strongly recognized $)$} \\
\hline $\begin{array}{l}\text { Recognition of Identity by } \\
\text { instructors, peers, and parents }\end{array}$ & 5.83 & 5.00 \\
\hline
\end{tabular}

(R.2) How does participating in CAPS mentoring affect their academic achievement and their preferences for pursuing challenging occupations and research? We compared the GPA's of CAPS scholars to peers who were matched on specific academic accomplishments (i.e. course progression). However, due to privacy concerns, we were not able to obtain financial need information from the matched group. Thus, whereas $100 \%$ of CAPS scholars have demonstrated financial hardship, the same cannot be said of their otherwise matched peers. As reflected in Table 4, the GPA of CAPS scholars began and remained slightly below their matched peers after one year in the CAPS program. One factor might be Phys II course. CAPS students, in particular CS students, were required to finish Phys II by spring 2019 whereas other CS students in the matched group tended to postpone to take it. As CS students were majority of the first cohort and their Phys II grades were generally lower than other course grades, we believe that the spring 2019 GPA is slightly lower. However, CAPS scholars reported a higher fealty to careers associated with their academic major relative to their matched peers, despite a lower intention to attend graduate school (Table 5).

\begin{tabular}{|l|r|r|}
\hline Table 4 & CAPS & \multicolumn{2}{c|}{ NON CAPS } \\
\hline & \multicolumn{2}{|c|}{$(\mathbf{1}=$ Strongly not recognized, $\mathbf{7}=$ Strongly recognized $)$} \\
\hline Spring 2018 GPA & 3.44 & 3.52 \\
\hline Spring 2019 GPA & 3.31 & 3.45 \\
\hline
\end{tabular}

\begin{tabular}{|c|c|c|}
\hline Table 5 & CAPS & NON CAPS \\
\hline Career plans & \multicolumn{2}{|c|}{$(1=$ not at all, $5=$ a great deal $)$} \\
\hline Intend an E/CS career & 4.83 & 4.5 \\
\hline Committed to E/CS career & 4.83 & 4.25 \\
\hline Intend to apply to Grad school & 3.5 & 4.0 \\
\hline Interest in Grad school & 4.0 & 4.0 \\
\hline
\end{tabular}

(R.3) What is the relationship, if any, between their perceptions and academic outcomes? Partial correlations predicting end-of-year GPA from engineering identity, while controlling for start-ofyear GPA trend in the predicted direction, but the sample is too small for such analyses to be 
reliable $(\mathrm{N}=7, \mathrm{r}=.55, \mathrm{p}=.33)$. The same is true for partial correlations predicting end-of-year GPA from the reported recognition of scholars' engineering identity by others, while controlling for start-of-year GPA $(\mathrm{N}=7, \mathrm{r}=.57, \mathrm{p}=.31)$. While not conclusive, these data suggest that the trends of higher engineering identity for CAPS scholars, and greater recognition of their engineering identity from their instructors/peers/family, as compared to their matched peers, may provide protective benefits as time moves forward.

(R.4) What is the impact on the trained advisors? During focus groups Mentors reported a benefit of having dedicated time to discuss the mentorship with their peers and borrow best practices from each other. For example, 2 out of 4 mentors reported immediate success in establishing relationships with their mentees, building off of their expertise developed in roles as mentors in previous programs. However, the other two mentors mentioned initial struggles connecting with students. These latter mentors cited discomfort around discussing the personal lives of their students, fearing the student's perception that they were overstepping their mentorship role. The two mentors that had early success building relationships then shared specific examples of their success with the group, focused on revealing one's own background (i.e., sharing stories of one's own immigration, revealing one's own college journey and struggles) as a means of building rapport with mentees. One mentor explained his strategy of building trust by only talking about family, and not academics, when first meeting mentees. This exchange provided an important benefit of intra-group training in mentorship for the two remaining mentors that may not have otherwise taken place.

Further, mentors developed higher standards for CAPS scholars as compared to non-CAPS mentees. "We have higher expectations...," one mentor noted about the scholars, adding that the mentors "challenge them more, because of course, their performance." Mentors reported that CAPS scholars are more engaged during meetings, noting "lots of questions about internships and resume-building," and observing that scholars were more likely to talk about internships than other students who are not scholars in the CAPS program. Such increased expectation for students has been previously shown to be an indicator of student success [18].

\section{Assessment and Evaluation}

Formative evaluation data was gathered by monitoring the implementation of the CAPS program activities conducted to achieve the program goals and by monitoring the implementation of the Mentor+ advisement and mentoring to participating scholars, and other student support activities such as field trips, seminar series, cohort social activities, etc. Between August 2018 and May 2019, three main CAPS evaluation activities were conducted. These activities include: CAPS Orientation for Students and Faculty Mentors, five CAPS Management Faculty Interviews and the CAPS student focus group.

During the CAPS Orientation on August 13, 2018, twelve CAPS students attended and completed a student intake form. Most students (92\%) indicated that their highest educational goal was an M.A. or M.S. Most students" (75\%) plans are "somewhat definite" or "very definite" (33\%). When asked about their commitment to the CAPS program, all respondents (100\%) agreed that they were either "committed" or "highly committed" to completing the CAPS program within 4 to 5 years. All students expressed a desire to work in a STEM-related career, 
where the majority (83\%) stated "very definite" plans to work in a STEM-related career and only a few (17\%) said they were "somewhat definite".

Students were asked to complete a survey evaluating the orientation. Eleven students completed the survey. All students $(100 \%)$ rated the orientation as "good", "very good", or "excellent". Some best-liked aspects of the orientation include: meeting/getting to know mentors and peers, playing "people bingo" and answering question during the icebreaker.

Faculty in attendance of the orientation were also asked to complete a survey. Four faculty mentors attended the orientation. All of the faculty (100\%), rated the orientation as either "very good" or "excellent". On a Likert scale of 1 to 5 (1=Poor; 5=Excellent), the average rating for different aspects of the training were rated between "Good" and "Excellent". Faculty rated the "Usefulness of information presented" the highest $(\mathrm{m}=4.6)$. On a scale of 1 (Not helpful) to 5 (Very helpful), faculty rated the presentation on "Understanding Concepts of Growth Mindset, Purpose and Value, and Social Belonging" an average of 4.8. The handson and role-play activities were rated an average of 3.8.

During the spring semester, the evaluation team conducted interviews with the PI, Co-PI, academic advisor and the faculty mentors. The main topics of these interviews included: the CAPS scholars, the CAPS program and future plans for year two of the grant. When asked about the caliber of CAPS students, the management team stated that they were "excellent students", "academically talented", "resilient", and "self-motivated". Two main challenges that scholars face was their need to develop their networking skills and their ability to balance their time with work and school. One area of success is the collaborative approach of leadership, allowing faculty and students to communicate and share feedback. Specific goals for year two focuses on integrating the new cohort into the program and establishing ties across the cohorts as well as with faculty mentors

During the end of the spring semester, a student focus group was conducted to collect student feedback on the first year of the program. Ten CAPS students participated in the focus group. On the strengths of the CAPS program, students liked having faculty mentors in the same field as them that they could turn to for advice, the scholarship money, ease of speaking with the CAPS management team, cohort-building and networking and the field trip to JPL. Students were also asked about their aspects of the program that need more improvement, these include: finding the time to meet with their faculty mentors, building the relationship with their mentors so they can address academic and personal issues and having more activities throughout the year.

Based on feedback and data gathered from the first year assessment, several changes have been made as explained in the previous sections. These changes include restructuring the orientation content to include new relationship building activities and clarification of the program expectations. In addition, the program shifted to empower students to be proactive in helping each other, with the introduction of scholar-initiated cohort building and peer mentoring programs, as well as the enhancement of mentor meetings by normalizing scholar initiated scheduling. Finally, we strengthened faculty mentor training with innovative techniques that could be implemented easily, despite the COVID19 related restrictions. 


\section{Conclusions and future work}

The paper described goals and activities of the CAPS program and its impact on academically talented, low-income students. The research analysis reported that the program made a positive impact on students to have strong engineering identity, sense of social belonging, and career interest in Engineering and Computer Science. As we continue to conduct longitudinal research with more students, the program will ensure a meaningful number of participations from the control group students and disaggregate data further, for example by major, gender, and URM, to answer our research questions in depth, identify which support and/or activity have the biggest impact on students' success, and address several long standing issues like retention. Our findings will help enhance the CAPS program and establish a sustainable Scholars Support Program at the university, which can be implemented with scholarships funded by other sources, and which can be transferred to similar culturally diverse institutions to increase success for students who have socio-economic challenges.

\section{Acknowledgement}

This material is based upon work supported by the National Science Foundation under Grant No. 1742614.

\section{References}

[1] NSF Scholarships in Science, Technology, Engineering, and Mathematics Program (SSTEM), https://www.nsf.gov/funding/pgm_summ.jsp?pims_id=5257.

[2] Scott Steinbrink, Karinna M. Vernaza, Barry J. Brinkman, and Lin Zhao, "A Rolling Stone: Evaluation of one NSF S-STEM Program through Successive Grant Periods," In Proc. ASEE Annual Conference, June 2018.

[3] Chip W Ferguson, Paul M Yanik, Yanjun Yan and Sudhir Kaul, "NSF S-STEM Scholarship Program Initiative via Recruitment, Innovation, and Transformation: SPIRIT Program Year-One Results,” In Proc. ASEE Annual Conference, June 2016.

[4] Eun-Young Kang, Jane Dong, Mathew Jackson, and Emily Allen, "Developing a Culturally Adaptive Pathway to Success," ASEE Annual Conference, June 2019.

[5] Shultz, E., Colton, G., Colton, C., "The Adventor Program: Advisement and Mentoring for Students of Color in Higher Education," Journal of Humanistic Counseling, Education and Development, v40 n2 p208-18, 2001.

[6] Rodgers, K. et al., "A Real PLUSS: An Intrusive Advising Program for Underprepared STEM Students,” NACADA Journal Volume 34(1), 2014.

[7] Allen, E., Castillo F., Schiorring, E. "Starting a New Conversation: An Engineering Faculty Advisor Development Program," Procs. Frontiers in Education Conference, Seattle, WA, 2012. 
[8] Allen, E., Castillo F., Schiorring, E. "The Reflective Engineering Advisor: a Paradigm for Learning-Centered Student Advising," Procs. American Society for Engineering Education Annual Conf., Atlanta, GA, 2013.

[9] Dong, J., Kang, E., \& Hidalgo, F., "Building a Collaborative Advising Structure through ECST Advising Council," presented at ASEE PSW 2019 Conference, Poster Symposium, Los Angeles, USA, 2019.

[10] Dong, J., \& Allen, E., "Work-in-Progress: Building an Inclusive Faculty Community Through the ECST Teaching and Learning Academy," ASEE Annual Conference, Florida, June 2019.

[11] Aronson, J., Fried, C. B., \& Good, C. (2002). "Reducing the effects of stereotype threat on African American college students by shaping theories of intelligence," Journal of Experimental Social Psychology, 38(2), 113-125.

[12] Dweck, C.S. (2006). Mindset: The new psychology of success. New York: Ballantine.

[13] Rattan, A., Good, C., \& Dweck, C. S. (2012). "It's ok-Not everyone can be good at math: Instructors with an entity theory comfort (and demotivate) students," Journal of Experimental Social Psychology, 48, 731-737.

[14] Yosso, T. J. (2005). Whose culture has capital? A critical race theory discussion of community cultural wealth. Race ethnicity and education, 8(1), 69-91.

[15] Tuberty, J., Anagnos, T., and Allen, E.L., "Leveraging Scholarships to Advance Student Success," Proceedings ASEE Zone IV Conference, Long Beach, CA, 2014.

[16] Rosenthal, K. I., \& Shinebarger, S. H., "Peer Mentors: Helping Bridge the Advising Gap," About Campus, 15.1 (2012): 24-27.

[17] Heirdsfield, A. M., Walker, S., Walsh, K., \& Wilss, L., "Peer mentoring for first-year teacher education students: The mentors' experience," Mentoring \& Tutoring: Partnership in Learning, 16.2 (2008): 109-124.

[18] Rosenthal, R., \& Jacobson, L. (1968). Pygmalion in the classroom. The urban review, 3(1), 16-20. 